\title{
Cold blood spinoplegia under motor-evoked potential monitoring during thoracic aortic surgery
}

\author{
Shinya Takahashi, MD, Kazumasa Orihashi, MD, Katsuhiko Imai, MD, Taketomo Mizukami, MD, \\ Taiichi Takasaki, MD, and Taijiro Sueda, MD
}

Objective: Motor-evoked potential monitoring is used to prevent paraplegia during thoracic aortic surgery. Multidetector computed tomography has been used preoperatively to detect the Adamkiewicz artery, but the hemodynamic significance of the Adamkiewicz artery is controversial. This study aims to evaluate whether the multidetector computed tomography-defined Adamkiewicz artery is hemodynamically essential and needs to be reconstructed with cold blood spinoplegia under motor-evoked potential monitoring.

Methods: From 2005 to 2008, both preoperative multidetector computed tomographic analysis and intraoperative neurogenic motor-evoked potential monitoring with cold blood infusion into the clamped segment of the aorta were done in 15 patients. A motor-evoked potential decrease to less than $50 \%$ of the initial value at 3 minutes after cold blood infusion determined the hemodynamic significance of the multidetector computed tomography-defined Adamkiewicz artery. Adamkiewicz arteries determined to be essential were reconstructed, and those determined to be nonessential were sacrificed.

Results: The Adamkiewicz artery was involved in the clamped segment of the aorta in 11 cases. After cold blood infusion, 8 patients experienced no significant motor-evoked potential decrease, and Adamkiewicz artery ligation was undertaken, whereas a moderate motor-evoked potential decrease was noted in 1 patient, prompting reconstruction. None of these 9 patients had permanent neurologic deficits. In 2 patients, the Adamkiewicz artery was reconstructed based on motor-evoked potential findings, with paraparesis occurring in 1 patient. In 4 patients without Adamkiewicz artery involvement in the clamped segment, there was no neurologic deficit.

Conclusions: Cold blood infusion accelerates motor-evoked potential changes and might enable decision making regarding the need for reconstruction of multidetector computed tomography-defined Adamkiewicz arteries. Cold blood-loaded motor-evoked potential is beneficial to minimize Adamkiewicz artery reconstruction time and limit spinal cord ischemia. (J Thorac Cardiovasc Surg 2011;141:755-61)

Paraplegia, paraparesis, or both remain serious complications of thoracic and thoracoabdominal aortic aneurysm repair and occur in $2 \%$ to $16 \%$ of patients ${ }^{1-5}$ despite the implementation of various adjunctive procedures, including distal perfusion, mild hypothermia, cerebrospinal fluid drainage, and protective drugs. Two strategies that are commonly accepted for preserving essential spinal cord perfusion are (1) preoperative identification of the Adamkiewicz artery (AKA) by means of 64-row multidetector computed tomographic angiographic (MDCTA) or magnetic resonance angiographic analysis and (2) intraoperative monitoring of the motor-evoked potential (MEP).

The former modalities enable visualization of the continuity of the intercostal or lumbar arteries, the greater radic-

\footnotetext{
From the Department of Cardiovascular Surgery, Hiroshima University Hospital, Hiroshima, Japan.

Disclosures: Authors have nothing to disclose with regard to commercial support.

Received for publication May 14, 2010; revisions received Aug 18, 2010; accepted for publication Sept 12, 2010; available ahead of print Nov 22, 2010.

Address for reprints: Shinya Takahashi, MD, 1-2-3, Kasumi, Minamiku, Hiroshima, Japan 732-0062 (E-mail: shiny@mte.biglobe.ne.jp).

0022-5223/ $\$ 36.00$

Copyright (c) 2011 by The American Association for Thoracic Surgery doi:10.1016/j.jtcvs.2010.09.056
}

ular artery, and the anterior spinal artery in more than $95 \%$ of patients. ${ }^{6-8}$ Despite preoperatively identified AKAs being elaborately reconstructed in many institutions to minimize the risk of spinal cord injury, they are often found to be occluded on postoperative assessment, suggesting that they were not necessarily essential.

MEP monitoring has proved to be a sensitive monitor of spinal cord ischemia and is beneficial to improving surgical outcomes. ${ }^{9,10}$ However, it can take longer than 10 minutes to determine ischemic changes of MEP in normothermia. For this reason, we introduced cold blood infusion into the clamped segment of the aorta, aiming to prompt MEP changes by topically cooling the spinal cord. ${ }^{11}$ The MEP amplitude significantly decreased within 3 minutes after cold blood infusion, whereas no patient showed delayed onset of MEP decrease. Cold blood-loaded MEP appeared to clearly delineate the presence or absence of MEP changes within 3 minutes.

Recently, Griepp and Griepp ${ }^{12}$ postulated the "collateral network theory" and reported excellent results. The intercostal and lumbar arteries between T7 and L1 were sacrificed while the MEP and somatosensory-evoked potential (SSEP) were monitored during thoracic and thoracoabdominal repair. ${ }^{13}$ These reports make us reconsider the significance of the AKA. 


$$
\begin{aligned}
& \text { Abbreviations and Acronyms } \\
& \text { AKA }=\text { Adamkiewicz artery } \\
& \text { CSF }=\text { cerebrospinal fluid } \\
& \mathrm{CT} \quad=\text { computed tomography } \\
& \mathrm{MDCTA}= \text { multidetector computed tomographic } \\
& \text { angiography } \\
& \mathrm{MEP} \quad= \text { motor-evoked potential } \\
& \mathrm{SSEP}=\text { somatosensory-evoked potential } \\
& \mathrm{TEE}=\text { transesophageal echocardiography } \\
& \text { TEVAR }=\text { thoracic endovascular aneurysm } \\
& \text { repair }
\end{aligned}
$$

Thus we hypothesize that (1) a prompt MEP decrease indicates hemodynamic significance of the AKA and need for reconstruction and (2) hemodynamic insignificance is responsible for an occlusion of the reconstructed AKA. The purpose of this article is to report the preliminary results of this study.

\section{MATERIALS AND METHODS Subjects}

From 2005 to 2008, 29 patients underwent aortic repair for descending thoracic or thoracoabdominal aortic aneurysms in our institute, excluding emergency cases. In 15 of these patients, preoperative assessment of the AKA was done with MDCTA, and MEP was monitored intraoperatively. In the remaining 14 patients, MEP monitoring was not used because the aneurysm was located proximal to the T6 level or far distal to the AKA visualized with MDCTA, or cold blood infusion was not performed because of aortic dissection with a large false lumen, and these patients were excluded from the study. Demographics of the patients are shown in Table 1. There were 11 male and 4 female patients with ages ranging from 59 to 86 years (mean age, $72.7 \pm 7.6$ years). All patients had several comorbidities, including hypertension. Seven patients had descending thoracic aortic aneurysms, and 7 patients had Crawford type I and 1 patient had Crawford type IV thoracoabdominal aortic aneurysms.

\section{Preoperative MDCTA Study}

Helical computed tomographic (CT) angiographic analysis was performed with a 64-row multidetector CT scanner (Light Speed VCT; GE Healthcare, Waukesha, Wis). After $100 \mathrm{~mL}$ of contrast medium was administered intravenously, scanning was started when the CT value in the lumen of the thoracic aorta (T7) reached 200 Hounsfield units. Three-dimensional image reconstruction was performed with analysis software (Virtual Place Raijin; AZE, Ltd, Tokyo, Japan). The AKA was defined as a continuous vessel from the aorta through the intercostal or lumbar artery and the radiculomedullary artery to the anterior spinal cord artery to eliminate venous signatures from being mistaken as arterial.

\section{MEP Monitoring}

Neurogenic MEP monitoring was used in every case to obtain discrete waveforms during adequate muscle relaxation. On the day before the operation, a pair of bipolar, platinum electrode catheters (UKG-100-5PM; Unique Medical, Tokyo, Japan) were placed in the dorsal epidural space for intraoperative evoked spinal cord potential monitoring: a stimulating electrode was placed at the C5-C6 level, and a recording electrode was placed at the lumbar level. A cerebrospinal fluid (CSF) drainage catheter was inserted at a low lumbar location (L3-L4).
After induction of anesthesia with fentanyl/remifentanyl and propofol with vecuronium bromide, a pair of bipolar, screw-type platinum electrodes was placed on the bilateral anterior parietal region for transcranial electrical stimulation of the cerebral motor cortices. A pair of bipolar surface electrodes was placed on the bilateral peroneal nerves for the SSEP. The MEPs and SSEPs were recorded at the lumbar electrodes. Stimulation and recordings were performed with the EpochXp system (Nihon Koden, Tokyo, Japan; Figure 1). The stimuli (MEP: intensity, $100 \mathrm{~mA}$; duration, $0.2-1.0 \mathrm{~ms}$, single pulse; SSEP: intensity, $25-50 \mathrm{~mA}$; duration, $0.2 \mathrm{~ms}$, single pulse) were delivered at a rate of 3.3 to $7.3 \mathrm{~Hz}$. Each evoked potential was filtered between 20 and $1500 \mathrm{~Hz}$ and was amplified by averaging a total of 20 to 50 responses. All data were stored in the hard disc of this system.

\section{Surgical Procedures}

The aorta was exposed through a left thoracotomy with or without a paramedian retroperitoneal approach. Femorofemoral partial cardiopulmonary bypass was established with a pump flow of 2.2 to $2.6 \mathrm{~L} \cdot \mathrm{min}^{-1}$. $\mathrm{m}^{-2}$ after intravenous injection of steroids and the oxygen radical scavenger edaravone. The rectal temperature was maintained at $34^{\circ} \mathrm{C}$. CSF drainage was continued for 2 days to maintain the CSF pressure at less than $10 \mathrm{~mm}$ $\mathrm{Hg}$. The distal perfusion pressure was maintained at a level higher than 60 $\mathrm{mm} \mathrm{Hg}$. The intercostal arteries, including the preoperatively identified AKA, were exposed.

After aortic crossclamping, cold blood $\left(4^{\circ} \mathrm{C}\right)$ was infused into the clamped segment of the aorta through a 14-gauge needle at a flow rate of 100 to $200 \mathrm{~mL} / \mathrm{min}$ for 3 minutes (Figure 2) while MEP amplitudes were monitored. The puncture site was carefully determined based on meticulous assessment by means of transesophageal echocardiographic (TEE) analysis, and cold blood inflow was visualized with TEE analysis to avoid unintended detachment of a mural thrombus. The amount of infused cold blood depended on the size of the aneurysm and ranged from 300 to 600 $\mathrm{mL}$.

\section{Decision Making Based on MEP Monitoring}

The AKA in the clamped segment was diagnosed as essential when the MEP amplitude decreased to a level less than $50 \%$ of the original amplitude after cold blood infusion within 3 minutes (Figure 3). In patients with a critical decrease in MEP, the AKA was immediately reconstructed after aortotomy with a vascular prosthesis (10 $\mathrm{mm}$ in diameter) or a saphenous vein and was perfused with warm blood at a flow rate of $40 \mathrm{~mL} / \mathrm{min}$ and a perfusion pressure of up to $150 \mathrm{~mm} \mathrm{Hg}$. After the aorta was repaired, this reconstructed intercostal graft was anastomosed to the main graft. When there was no decrease of MEP amplitude after cold blood infusion, the AKA identified by means of preoperative MDCTA study was determined to be not essential and was ligated extraluminally before opening the aneurysm. If the other intercostal arteries were exposed, they were also ligated extraluminally before opening the aneurysm; otherwise, they were ligated intraluminally.

\section{RESULTS}

A total of 17 AKAs were identified in 15 patients undergoing preoperative MDCTA analysis: a single AKA in 13 patients and 2 AKAs in 2 patients. The AKA entered the spinal canal at T7 (2 AKAs), T9 (3 AKAs), T10 (5 AKAs), T11 (3 AKAs), T12 (2 AKAs), or L1 (2 AKAs). Fifteen AKAs were on the left side, and 2 AKAs were on the right side. No complications related to the placement of epidural electrodes for MEP monitoring were encountered in any case.

Duration of the operation, duration of extracorporeal circulation, and aortic clamp time were $418 \pm 182,92 \pm 40$, 
TABLE 1. Patients' characteristics

\begin{tabular}{lc}
\hline No. of patients & 15 \\
Age, y (range) & $72.7 \pm 7.6(59-86)$ \\
Sex (male/female) & $11 / 4$ \\
Preoperative variables & \\
Hypertension & $13(87 \%)$ \\
Hyperlipidemia & $4(27 \%)$ \\
Diabetes mellitus & $3(20 \%)$ \\
COPD & $1(7 \%)$ \\
Coronary artery disease & $4(27 \%)$ \\
Renal insufficiency & $2(13 \%)$ \\
Cerebral infarction & $1(7 \%)$ \\
Smoking & $4(27 \%)$ \\
Marfan syndrome & $0(0 \%)$ \\
Coactation of aorta & $0(0 \%)$ \\
Previous chest pain & $3(20 \%)$ \\
Aortic dissection & $4(27 \%)$ \\
Traumatic & $0(0 \%)$ \\
Aortic infection & $0(0 \%)$ \\
Aortic rupture & $0(0 \%)$ \\
\hline COPD, Chronic obstructive pulmonary disease
\end{tabular}

and $77 \pm 31$ minutes, respectively. There was no paraplegia, but 1 patient experienced paraparesis caused by cerebral infarction, probably secondary to multiple thromboembolism during the proximal aortic clamping. There were no operative or hospital deaths.

Table 2 shows the level of the AKAs, involvement of the AKA in the aneurysm, changes in MEP amplitudes, and surgical outcomes. Although the AKA was not involved in the clamped segment of the aorta in 4 patients (patients 1-4), the origin of the AKA was within the clamped segment in 11 patients (patients 5-15). In the former 4 patients, there were no MEP changes after cold blood infusion. No neurologic deficit was encountered in any of these patients. Among the latter 11 patients, there was no significant MEP decrease within 3 or 20 minutes in 7 patients (patients 5-11). Although every intercostal artery in the clamped segment, including the supposed AKA, was ligated, none of them presented with neurologic deficit. The MEP amplitude decreased but remained at a level greater than $50 \%$ of the initial value in 2 patients (patients 12 and 13). Delayed MEP decrease within 20 minutes was not appreciated in either of these patients. The AKA was ligated in both patients, but it was finally reconstructed in 1 patient because of the reason described below. The MEP amplitude decreased to a level less than $50 \%$ of the initial value in only 2 patients (patients 14 and 15), both of whom underwent reconstruction of the AKAs.

Although patient 12 presented with a gradual decrease of MEP to $70 \%$ of the initial value during the operation, motor function of the lower limb was temporarily restricted after the operation and was recovered during the hospital stay. Patient 13, who had previous repair of the proximal thoracic aorta for acute aortic dissection, underwent replacement of the distal descending aorta. The MEP amplitude decreased to $70 \%$ at 3 minutes of cold blood infusion and gradually recovered to the initial level. However, the MEP amplitude decreased to $70 \%$ again during a period of hypotension caused by sustained bleeding and did not recover to the

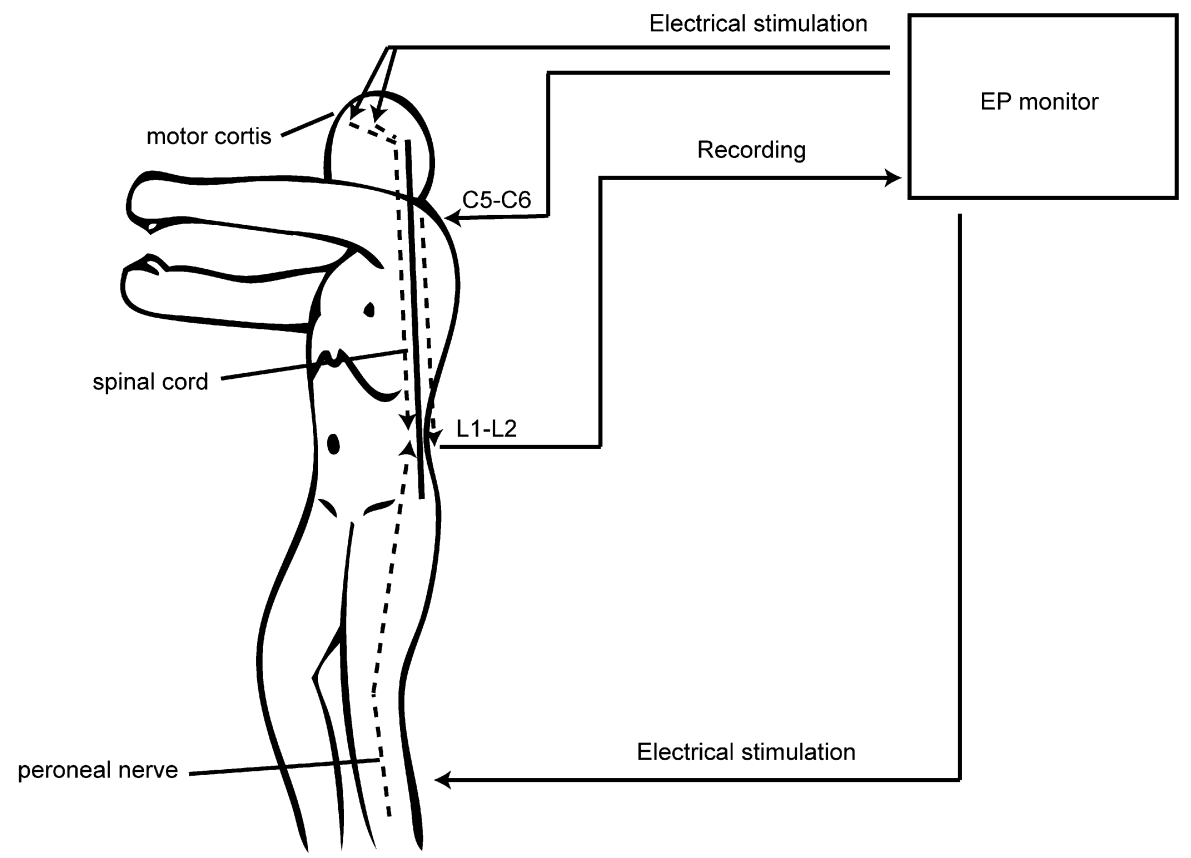

FIGURE 1. Evoked potential ( $E P$ ) monitoring system and conduction pathway of evoked potential (dotted line). Transcranial electrical stimulation passed through motor cortices and the spinal cord was recorded by using the epidural electrode (L1-L2; transcranial motor-evoked potential). Descending evoked spinal cord potentials (C5-C6 to L1-L2) and somatosensory-evoked potentials (peroneal nerve to L1-L2) were also recorded for multilateral observation. 


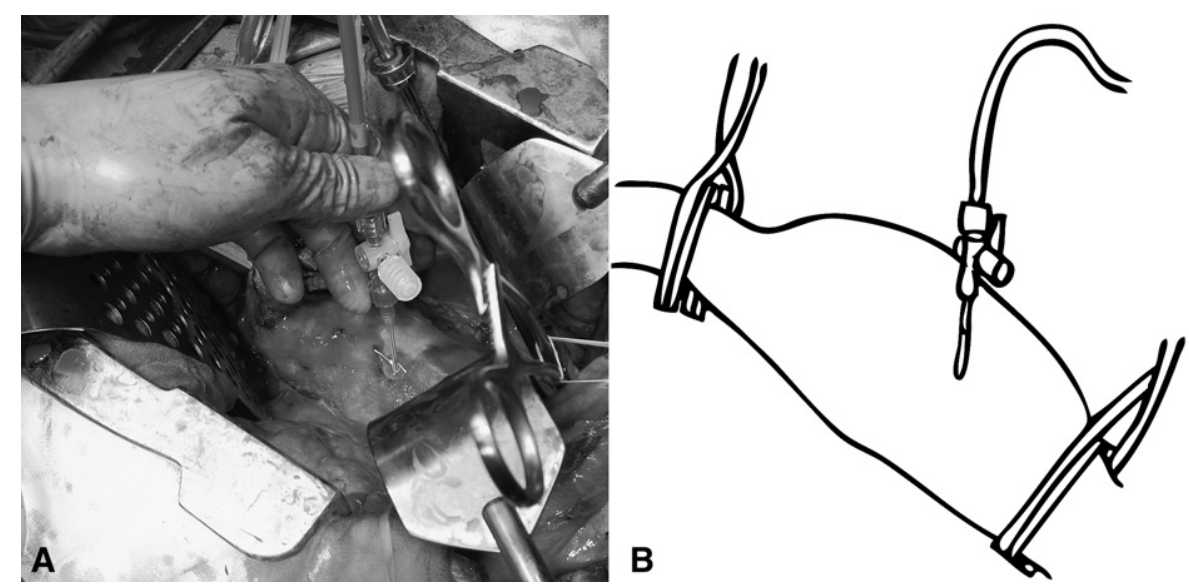

FIGURE 2. Procedure of cold blood infusion. A, A 14-gauge needle was punctured into the aorta. B, Schema of the picture. Cold blood was infused into the clamped segment of the aorta.

initial level. In this case, we initially ligated the AKA but decided to reconstruct the AKA at T10 to ensure adequate blood flow because the spinal cord perfusion appeared to be partially dependent on the AKA. This patient did not have a neurologic deficit. Postoperative CT scanning showed occlusion of the reconstructed intercostal artery.

In patients 14 and 15, the intercostal arteries were reconstructed based on the significant and immediate MEP changes. In patient 14, the MEP recovered after reperfusion, and no neurologic deficit developed. In patient 15 , however, MEP disappeared at one point and later recovered, although only to $50 \%$ of the initial level. Aortic perfusion pressure was maintained at greater than $100 \mathrm{~mm} \mathrm{Hg}$ during the operation and during the postoperative period. The patient in this case had paraparesis postoperatively. In this patient, the aorta was diffusely and severely atherosclerotic, and fragile intima was likely to have caused left cerebral infarction from a multiple thromboembolism caused by proximal aortic clamping. Furthermore, selective perfusion of the intercostal artery was not feasible because of atherosclerotic stenosis of the AKA, and ischemic time was prolonged.
Postoperatively CSF drainage pressure increased to greater than $15 \mathrm{~mm} \mathrm{Hg}$, and CSF drainage was continued. The cranial magnetic resonance image showed multiple left cerebral infarctions. The left upper limb function was normal, but the left lower limb movement was impaired, which was unexplainable based on the cranial magnetic resonance image. Therefore we concluded that the patient had lower limb paraparesis with right hemiplegia caused by both stroke and spinal cord ischemia.

\section{DISCUSSION}

Despite the fact that thoracic endovascular aneurysm repair (TEVAR) has achieved a lower incidence of paraplegia and paraparesis than open surgical intervention, neurologic complications have not been completely eliminated, suggesting a possibility of occluding the essential AKA by the endovascular graft. ${ }^{14}$ Siegenthaler and associates ${ }^{15}$ reported delayed temporary paraparesis that appeared after successful TEVAR, but the deficit was corrected by increasing the blood pressure. These findings indicate that spinal cord perfusion depends not solely on AKAs but partially
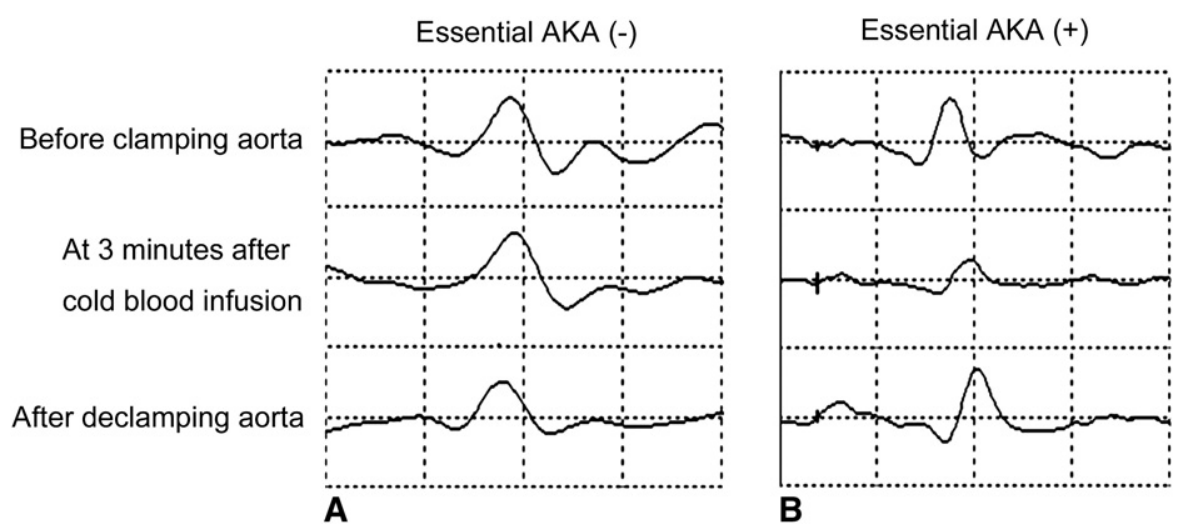

FIGURE 3. Changes in motor-evoked potential (MEP). A, MEP amplitude did not change. B, MEP amplitude decreased after cold blood infusion within 3 minutes and was restored after Adamkiewicz artery $(A K A)$ reconstruction and declamping of the aorta. 
TABLE 2. MDCTA-defined AKA and results

\begin{tabular}{|c|c|c|c|c|c|c|c|c|}
\hline \multirow{2}{*}{$\begin{array}{c}\text { Patients } \\
\text { no. }\end{array}$} & \multirow{2}{*}{$\begin{array}{c}\text { Type of } \\
\text { aneurysm }\end{array}$} & \multirow[b]{2}{*}{ AKA (MDCTA) } & \multirow{2}{*}{$\begin{array}{c}\text { AKA in } \\
\text { aneurysm }\end{array}$} & \multirow{2}{*}{$\begin{array}{c}\text { MEP at } \\
3 \text { min } \\
\end{array}$} & \multicolumn{2}{|c|}{ Amplitude (\%) } & \multirow{2}{*}{$\begin{array}{c}\text { Reconstruction of } \\
\text { branch artery }\end{array}$} & \multirow{2}{*}{$\begin{array}{c}\text { Neurologic } \\
\text { outcome }\end{array}$} \\
\hline & & & & & Lowest & At end & & \\
\hline 1 & DTAA & T9L, T12L & $\mathrm{N}$ & $100 \%$ & $100 \%$ & $100 \%$ & None & No deficit \\
\hline 2 & DTAA & $\mathrm{T} 11 \mathrm{~L}$ & $\mathrm{~N}$ & $100 \%$ & $100 \%$ & $100 \%$ & None & No deficit \\
\hline 3 & I & $\mathrm{T} 12 \mathrm{~L}$ & $\mathrm{~N}$ & $100 \%$ & $100 \%$ & $100 \%$ & None & No deficit \\
\hline 4 & IV & $\mathrm{T} 11 \mathrm{~L}$ & $\mathrm{~N}$ & $100 \%$ & $100 \%$ & $100 \%$ & None & No deficit \\
\hline 5 & DTAA & $\mathrm{T} 7 \mathrm{~L}$ & Y & $100 \%$ & $100 \%$ & $100 \%$ & None & No deficit \\
\hline 6 & DTAA & $\mathrm{T} 7 \mathrm{~L}$ & Y & $100 \%$ & $100 \%$ & $100 \%$ & None & No deficit \\
\hline 7 & I & T9R & Y & $100 \%$ & $100 \%$ & $100 \%$ & None & No deficit \\
\hline 8 & DTAA & T10R & Y & $100 \%$ & $100 \%$ & $100 \%$ & None & No deficit \\
\hline 9 & I & $\mathrm{T} 11 \mathrm{~L}$ & Y & $100 \%$ & $100 \%$ & $100 \%$ & None & No deficit \\
\hline 10 & I & T9L & Y & $100 \%$ & $80 \%$ & $100 \%$ & None & No deficit \\
\hline 11 & DTAA & $\mathrm{T} 10 \mathrm{~L}$ & Y & $100 \%$ & $70 \%$ & $100 \%$ & None & No deficit \\
\hline 12 & I & L1L & Y & $80 \%$ & $70 \%$ & $70 \%$ & None & No deficit \\
\hline 13 & I & T10L, L1L & Y & $70 \%$ & $70 \%$ & $80 \%$ & $\mathrm{~T} 10 \mathrm{~L}$ & No deficit \\
\hline 14 & DTAA & T10L & Y & $45 \%$ & $45 \%$ & $90 \%$ & $\mathrm{~T} 10 \mathrm{~L}$ & No deficit \\
\hline 15 & I & T10L & Y & $40 \%$ & $0 \%$ & $50 \%$ & $\mathrm{~T} 10 \mathrm{~L}$ & Paraparesis \\
\hline
\end{tabular}

The patients are in order in relation to motor-evoked potential change and not in chronologic order. Reconstructed branch arteries were patent in patients 13 and 14 and occluded in patient 15. MDCTA, Multidetector computed tomographic angiography; AKA, Adamkiewicz artery; $M E P$, motor-evoked potential; DTAA, descending thoracic aortic aneurysm.

on collateral circulation, although the latter can be inadequate under low perfusion pressure.

The role of collateral circulation has been emphasized in the collateral network concept of Griepp and Griepp. ${ }^{12} \mathrm{Etz}$ and colleague ${ }^{13}$ reported that sacrifice of the intercostal and lumbar arteries during thoracic and thoracoabdominal aortic aneurysm repair resulted in low rates of immediate and delayed paraplegia. They described a patient with immediate paraplegia who experienced precipitating intraoperative dissection resulting in 6 hours of lower body ischemia. This case indicates the importance of collateral circulation.

Two questions arise. First, should every AKA be elaborately reconstructed at a risk of prolonged ischemia of the spinal cord? Second, is it the best strategy to create a situation in which spinal cord perfusion depends only on collateral circulation? A possible solution is to reconstruct only the essential AKAs and sacrifice the other nonessential AKAs to minimize the ischemic insult on the spinal cord.

Improved quality of 64-row MDCTA and magnetic resonance angiography has enabled visualization of AKAs in more than $95 \%$ of cases. ${ }^{6-8}$ Three-dimensional CT images discretely visualize the continuity from the intercostal artery to the anterior spinal cord artery and facilitate identification of the AKA in the operative field. This development has led to a situation that AKAs need to be reconstructed in most cases, and the majority of grafts are found to be occluded postoperatively. ${ }^{16}$ It is unclear whether the occluded graft was effective in avoiding spinal cord ischemia in the perioperative period or whether reconstruction was even necessary. A considerably lower incidence of paraplegia after TEVAR, despite occlusion of every branch artery, appears to support the latter. In another respects, however, TEVAR might create a new Achilles heel: persistent susceptibility to hypotension, even if the patient can survive the neurologic deficit in the acute phase. Thus it is desirable to identify and reconstruct only the essential AKAs among the morphologically defined AKAs.

We previously reported that cold blood infusion into the clamped segment of the aorta induces a rapid change in MEP amplitude. ${ }^{11}$ A decrease in MEP amplitude might be related to local hypothermia by cold blood. ${ }^{5}$ Ueno and coworkers ${ }^{17}$ reported that intra-aortic infusion of cold lactated Ringer's solution $\left(3^{\circ} \mathrm{C}\right)$ cooled the spinal cord by $6^{\circ} \mathrm{C}$ to $7^{\circ} \mathrm{C}$. Because hypothermia induces a decreased electrophysiologic response in cerebral and peripheral neurologic activity, ${ }^{18,19}$ an immediate MEP decrease is likely to be caused by cooling of the spinal cord. Furthermore, because cold blood saturated with oxygen is infused, infusion of cold blood does not induce spinal cord ischemia and just accelerates MEP changes. We hypothesized that cold blood infused into the essential AKA topically cools the spinal cord and decreases MEP amplitude. We did not perform a morphologic assessment but rather a functional assessment.

In this study, as well as a previous study, the MEP was recorded at the intrathecal electrode (neurogenic MEP). ${ }^{11,20}$ The advantage of a neurogenic MEP is a simple waveform compared with a compound waveform recorded in a myogenic MEP. ${ }^{13,21}$ However, it takes a longer time to detect ischemic changes in a neurogenic MEP than in a myogenic MEP. de Haan and associates ${ }^{22}$ reported that the median time to a 50\% reduction in epidural and myogenic MEP amplitudes after aortic occlusion was 11.3 minutes and within 2 minutes, respectively. We previously showed that an MEP decrease was caused by cooling of the spinal cord in a dog model. ${ }^{23}$ Despite the longer time to detect changes in neurogenic MEP during ischemia, cold blood infusion might be helpful for identifying 
hemodynamically significant AKAs based on an early change in the neurogenic MEP.

We routinely monitor both afferent and efferent conduction to check for damage of the spinal cord or in case the MEP recording is unexpectedly interrupted for some unknown reason. SSEPs were used to distinguish between spinal cord ischemia and systemic factors or technical problems. The monitoring of both MEPs and SSEPs is considered to be a safety system to prevent spinal cord ischemia.

Our current strategy for descending aortic repair is described as follows:

(1) If there is no AKA in the clamped segment, the branched arteries are not preserved.

(2) If the AKA is present in the clamped segment, MEP changes after cold blood infusion into the clamped segment of aorta are monitored.

(a) Without a significant MEP change, the AKA is not reconstructed.

(b) When MEP amplitude decreases to a level less than $50 \%$ of the initial value, the AKA is determined to be essential and is reconstructed.

The cutoff value of MEP amplitude as 50\% of the baseline value is based on the report of van Dongen and coworkes ${ }^{10}$ that the relative risks of paraplegia in patients with an MEP amplitude of $50 \%$ or less than the baseline value after 5 minutes of reperfusion and during closure of the skin were 21.7 and 30.9 times higher, respectively, compared with those of patients with an MEP of greater than $50 \%$ of the baseline value. We evaluated the MEP changes at 3 minutes after cold blood infusion based on the findings in our previous studies. ${ }^{11,20}$ The MEP amplitude did not decrease to a level less than $50 \%$ of the baseline value after 3 minutes of cold blood infusion in any patient unless there was an apparent cause, such as considerable systemic hypotension. If our hypothesis was wrong, neurologic deficit should have occurred in several patients in whom the AKA in the clamped segment of the aorta was sacrificed (patients 5-12). In this series, MEP amplitude was unchanged after cold blood infusion in 7 of 11 patients, and this might explain the high incidence of graft occlusion of reconstructed AKAs.

It remains uncertain whether the AKA should be revascularized when the decrease in MEP amplitude is mild. ${ }^{20}$ Kawanishi and colleagues ${ }^{24}$ reported that 8 of 9 patients whose MEP amplitude decreased to less than $75 \%$ of baseline value at the end of the procedure had a neurologic deficit postoperatively. Because our study had a small number of patients, it is difficult to make a definitive conclusion, especially when the MEP is between $50 \%$ and $99 \%$ of the baseline value. In 2 patients, the MEP amplitude decreased to $70 \%$ to $80 \%$ of the baseline value. Although
1 patient had no paraplegia with the immediate decision to reconstruct the AKA, postoperative $\mathrm{CT}$ scanning revealed occlusion of the reconstructed intercostal artery, and this patient often noticed discomfort and slight palsy of the lower limbs during periods of hypotension associated with daily hemodialysis. The other patient had a transient paraparesis, probably as a result of sustained hypotension, which was caused by a large amount of oozing from the broadly dissected surface in this redo case. The events in these patients appear to be comparable with those in the patient undergoing successful TEVAR with delayed paraplegia caused by hypotension. These results suggest that the AKA should be reconstructed if there is any decrease in MEP amplitude. Hypotension during the operation and the postoperative period should be avoided. This will be our new strategy in the future based on the results of the current study.

Neurologic deficit in surgical cases is likely to be caused by (1) occlusion of the essential AKA, (2) intraoperative hypotension that leads to hypoperfusion of the spinal cord for a prolonged period of time, or both. Acher and associates ${ }^{25}$ reported desirable outcomes of descending aortic surgery by maintaining the blood pressure at greater than $90 \mathrm{~mm}$ $\mathrm{Hg}$ and mentioned that the mean arterial pressure during aortic clamping was a significant factor for paralysis. By using a multidisciplinary strategy in aortic surgery, the incidence of neurologic deficit can be decreased to a level comparable with that of TEVAR. Reconstruction of all AKAs detected in the preoperative assessment can adversely prolong the duration of cardiopulmonary bypass and increase the amount of bleeding. It might be beneficial to limit the number of reconstructions by identifying the essential functional AKA by means of MEP monitoring under cold blood infusion. If the essential AKA can be successfully reconstructed without neurologic deficit, it can be beneficial in reducing the future risk against unpredicted hypotension in various situations.

In 4 patients (patients 1-4), the AKA was located close to the aneurysm on the preoperative CT scan, and there was a risk of including this artery in the clamped segment. The level of the aortic clamp might be altered when the anastomosis is difficult. In such a situation, the nearby AKA can be included in the clamped segment. Thus we have used our method in these patients and included it in this study.

The small number of patients in the current series is a limitation of this study. Nevertheless, our preliminary results demonstrate that the majority of MDCTA-defined AKAs can be sacrificed without neurologic sequelae. The need for puncture and cold blood infusion into the aneurysm can be another limitation because it might raise a concern of possible thromboembolism. However, careful TEE assessment for an appropriate puncture site and subsequent observation during infusion has shown that this procedure can be safely performed. 
In conclusion, cold blood-loaded MEP monitoring might enable identification of the hemodynamically essential AKAs among the commonly visualized AKAs with preoperative MDCTA analysis. Although the nonessential AKAs thus defined by our criteria could be sacrificed without significant neurologic complications, we need further investigation in a case of an MEP decreasing to a level greater than $50 \%$. This method might be useful for efficiently repairing the aorta with AKA reconstruction to mitigate against the effects of further unpredicted hypotension.

\section{References}

1. Griepp RB, Ergin MA, Galla JD, Lansman S, Khan N, Quintana C, et al. Looking for the artery of Adamkiewicz: a quest to minimize paraplegia after operations for aneurysms of the descending thoracic and thoracoabdominal aorta. J Thorac Cardiovasc Surg. 1996;112:1202-15.

2. Svensson LG, Crawford ES, Hess KR, Coselli JS, Safi HJ. Experience with 1509 patients undergoing thoracoabdominal aortic operations. J Vasc Surg. 1993;17: 357-70.

3. Grabitz K, Sandmann W, Stuhmeier K, Mainzer B, Godehardt E, Ohle B, et al. The risk of ischemic spinal cord injury in patients undergoing graft replacement for thoracoabdominal aortic aneurysms. J Vasc Surg. 1996;23:230-40.

4. Safi HJ, Campbell MP, Miller CC 3rd, Iliopoulos DC, Khoynezhad A, Letsou GV, et al. Cerebral spinal fluid drainage and distal aortic perfusion decrease the incidence of neurological deficit: the results of 343 descending and thoracoabdominal aortic aneurysm repairs. Eur J Vasc Endovasc Surg. 1997; 14:118-24.

5. Coselli JS. The use of left heart bypass in the repair of thoracoabdominal aortic aneurysms: current techniques and results. Semin Thorac Cardiovasc Surg. 2003; 15:326-32.

6. Nakayama Y, Awai K, Yanaga Y, Nakaura T, Funama Y, Hirai T, et al. Optimal contrast medium injection protocols for the depiction of the Adamkiewicz artery using 64-detector CT angiography. Clin Radiol. 2008;63:880-7.

7. Boll DT, Bulow H, Blackham KA, Aschoff AJ, Schmitz BL. MDCT angiography of the spinal cord vasculature and the artery of Adamkiewicz. Am J Roentgenol. 2006; 187:1054-60.

8. Nijenhuis RJ, Jacobs MJ, Schurink GW, Kessels AG, van Engelshoven JM, Backes WH. Magnetic resonance angiography and neuromonitoring to assess spinal cord blood supply in thoracic and thoracoabdominal aortic aneurysm surgery. J Vasc Surg. 2007;45:71-7.

9. Jacobs MJ, Mess WH. The role of evoked potential monitoring in operative management of type I and type II thoracoabdominal aortic aneurysms. Semin Thorac Cardiovasc Surg. 2003;15:353-64.

10. van Dongen EP, Schepens MA, Morshuis WJ, ter Beek HT, Aarts LP, de Boer A, et al. Thoracic and thoracoabdominal aortic aneurysm repair: use of evoked potential monitoring in 118 patients. J Vasc Surg. 2001;34 1035-40.

11. Sueda T, Okada K, Orihashi K, Sugawara Y, Kouchi K, Imai K. Cold blood spinal cord plegia for prediction of spinal cord ischemia during thoracoabdominal aneurysm repair. Ann Thorac Surg. 2002;73:1155-9.

12. Griepp RB, Griepp EB. Spinal cord perfusion and protection during descending thoracic and thoracoabdominal aortic surgery: the collateral network concept. Ann Thorac Surg. 2007;83:S865-92.

13. Etz CD, Halstead JC, Spielvogel D, Shahani R, Lazala R, Homann TM, et al Thoracic and thoracoabdominal aneurysm repair: is reimplantation of spinal cord arteries a waste of time? Ann Thorac Surg. 2006;82:1670-7.

14. Kotelis D, Geisbusch P, von Tengg-Kobligk H, Allenberg JR, Bockler D. [Paraplegia after endovascular repair of the thoracic and thoracoabdominal aorta]. Zentralbl Chir. 2008;133:338-43.

15. Siegenthaler MP, Weigang E, Brehm K, Euringer W, Baumann T, Uhl M, et al Endovascular treatment for thoracoabdominal aneurysms: outcomes and results. Eur J Cardiothorac Surg. 2008;34:810-9.

16. Svensson LG. Intraoperative identification of spinal cord blood supply during repairs of descending aorta and thoracoabdominal aorta. J Thorac Cardiovasc Surg. 1996;112:1455-61.

17. Ueno T, Furukawa K, Katayama Y, Itoh T. Protection against ischemic spinal cord injury: one-shot perfusion cooling and percutaneous topical cooling. J Vasc Surg. 1994;19:882-7.

18. Stecker MM, Cheung AT, Pochettino A, Kent GP, Patterson T, Weiss SJ, et al. Deep hypothermic circulatory arrest: I. Effects of cooling on electroencephalogram and evoked potentials. Ann Thorac Surg. 2001;71:14-21.

19. Stecker MM, Cheung AT, Pochettino A, Kent GP, Patterson T, Weiss SJ, et al Deep hypothermic circulatory arrest: II. Changes in electroencephalogram and evoked potentials during rewarming. Ann Thorac Surg. 2001;71:22-8.

20. Hamaishi M, Orihashi K, Takahashi S, Isaka M, Okada K, Sueda T. Transcranial motor-evoked potentials following intra-aortic cold blood infusion facilitates detection of critical supplying artery of spinal cord. Eur J Cardiothorac Surg. 2008; 33:695-9.

21. de Haan P, Kalkman CJ, de Mol BA, Ubags LH, Veldman DJ, Jacobs MJ. Efficacy of transcranial motor-evoked myogenic potentials to detect spinal cord ischemia during operations for thoracoabdominal aneurysms. $J$ Thorac Cardiovasc Surg. 1997;113:87-101.

22. de Haan P, Kalkman CJ, Ubags LH, Jacobs MJ, Drummond JC. A comparison of the sensitivity of epidural and myogenic transcranial motor-evoked responses in the detection of acute spinal cord ischemia in the rabbit. Anesth Analg. 1996;83 1022-7.

23. Kumagai H, Sugawara Y, Isaka M, Okada K, Orihashi K, Sueda T. Cold saline injection attenuates motor-evoked potential in the spinal cord by cortical electrical stimulation in the dog. Hiroshima J Med Sci. 2005;54:77-82.

24. Kawanishi Y, Munakata H, Matsumori M, Tanaka H, Yamashita T, Nakagiri K, et al. Usefulness of transcranial motor evoked potentials during thoracoabdominal aortic surgery. Ann Thorac Surg. 2007;83:456-61.

25. Acher CW, Wynn MM, Mell MW, Tefera G, Hoch JR. A quantitative assessment of the impact of intercostal artery reimplantation on paralysis risk in thoracoabdominal aortic aneurysm repair. Ann Surg. 2008;248:529-40. 